\title{
The fibre size and content of the radial and sural nerves
}

\author{
D. J. O'SULLIVAN' ${ }^{1}$ AND M. SWALLOW' \\ From the Institute of Neurology, Queen Square, London
}

In a previous study of the human anterior tibial nerve (Swallow, 1966), it was concluded that 'the wide range of variation found in young as well as old subjects would seem to limit the usefulness of anterior tibial nerve biopsy as a diagnostic procedure in patients with generalized neurological disease'.

The present work was undertaken to establish the range of variation in the fibre size and content of the sural and radial nerves, and to assess their suitability for diagnostic biopsy.

\section{MATERIALS AND METHODS}

Specimens of radial and sural nerves were taken at necropsy from subjects without evidence of peripheral nerve disease. The age, sex, and cause of death in each case are shown in Table $I$.

The radial nerve was exposed on the lateral side of the wrist where it overlies the head of the radius. At this level some branching had already occurred, the nerve consisting of one main branch with one or more smaller branches accompanying it. Only the main branch was taken for study. Specimens were obtained from 21 cases, nerves being taken from both wrists in six subjects; in all, 27 radial nerves were examined.

The sural nerve was exposed behind the lateral malleolus. In three cases a single nerve trunk was present at this level, but in the remainder some branching had occurred; the largest branch was then taken for study. Specimens were obtained from 23 cases, nerves being taken from both ankles in four patients; in all, 27 sural nerves were examined.

About $1 \mathrm{~cm}$ of each nerve was removed; the specimen was gently stretched over a small piece of card, to which the ends were made to adhere by light pressure. Mounting under slight tension ensured. that the nerve remained straight during the subsequent preparation. After mounting, the specimens were placed immediately into Flemming's solution at room temperature for 18 to $24 \mathrm{hr}$. They were then dehydrated in alcohol and embedded in paraffin. Sections $5 \mu$ thick were cut and stained with Kultschitzky's haematoxylin, as described by Gutmann and Sanders (1943). They were then dehydrated, cleared, and mounted.

'Overseas Scholar, Royal Australasian College of Physicians.

'Present address: Royal Victoria Hospital, Grosvenor Road, Belfast.
TABLE I

DETAILS OF SUBJECTS STUDIED

Case no. Age Sex Nerve Source Diagnosis studied

\begin{tabular}{|c|c|c|c|c|c|}
\hline $\begin{array}{ll}1 & (4) \\
2 & (5) \\
3 & (6) \\
4 & (7) \\
5 & (12) \\
6 & (11) \\
7 & (13)\end{array}$ & $\begin{array}{l}22 \\
17 \\
46 \\
65 \\
55 \\
34 \\
68\end{array}$ & $\begin{array}{l}\mathbf{M} \\
\mathbf{M} \\
\mathbf{M} \\
\mathbf{F} \\
\mathbf{M} \\
\mathbf{M} \\
\mathbf{F}\end{array}$ & $\begin{array}{l}\mathbf{R} \\
\mathbf{R} \\
\mathbf{R} \\
\mathbf{R} \\
\mathbf{R}: \mathbf{S} \\
\mathbf{R}: \mathbf{S} \\
\mathbf{R}: \mathbf{S}\end{array}$ & $\begin{array}{l}\mathbf{C} \\
\mathbf{C} \\
\mathbf{C} \\
\mathbf{C} \\
\mathbf{C} \\
\mathbf{H} \\
\mathbf{H}\end{array}$ & $\begin{array}{l}\text { Carbon monoxide poisoning } \\
\text { Road traffic accident } \\
\text { Coronary thrombosis } \\
\text { Road traffic accident } \\
\text { Coronary thrombosis } \\
\text { Subacute bacterial endocarditis } \\
\text { Intracranial tumour } \\
\text { (meningioma) }\end{array}$ \\
\hline $8(14)$ & 39 & $\mathbf{F}$ & $\mathbf{R}: \mathbf{S}$ & $\mathbf{H}$ & Intracranial tumour (glioma) \\
\hline $9(16)$ & 47 & $\mathbf{M}$ & $\mathbf{R}: \mathbf{S}$ & $\mathbf{H}$ & Intracranial tumour (glioma) \\
\hline $10(17)$ & 57 & $\mathbf{M}$ & $\mathbf{R}: \mathbf{S}$ & $\mathbf{H}$ & Intracranial tumour (glioma) \\
\hline (18) & 63 & $\mathbf{M}$ & $\mathbf{R}$ & C & Carbon monoxide poisoning \\
\hline $12(19)$ & 71 & $\mathbf{M}$ & $\mathbf{R}$ & C & Myocardial failure \\
\hline $3(20)$ & 55 & $\mathbf{M}$ & $\mathbf{R}$ & $\mathbf{H}$ & Subarachnoid haemorrhage \\
\hline $4(21)$ & 28 & $\mathbf{M}$ & $\mathbf{R}$ & $\mathbf{H}$ & iccident \\
\hline $15(22)$ & 62 & $\mathbf{F}$ & $\mathbf{R}$ & $\mathbf{H}$ & I haemorrhage \\
\hline $16(23)$ & 63 & $\mathbf{M}$ & $\mathbf{R}$ & $\mathbf{H}$ & Cerebral haemorrhage \\
\hline 17 & 30 & $\mathbf{F}$ & $\mathbf{R}: \mathbf{S}$ & $\mathbf{H}$ & Colloid cyst of 3 rd ventricle \\
\hline 18 & 26 & $\mathbf{F}$ & $\mathbf{R}: \mathbf{S}$ & $\mathbf{H}$ & Pituitary tumour \\
\hline 19 & 26 & $\mathbf{M}$ & $\mathbf{S}$ & $\mathbf{H}$ & Intracranial tumour (glioma) \\
\hline 20 & 45 & $\mathbf{M}$ & $\mathbf{S}$ & $\mathbf{H}$ & Cerebral thrombosis \\
\hline 21 & 50 & $\mathbf{F}$ & $\mathbf{S}$ & $\mathbf{H}$ & Subarachnoid haemorrhage \\
\hline 22 & 48 & $\mathbf{F}$ & $\mathbf{R}$ & $\mathbf{H}$ & Pituitary adenoma \\
\hline 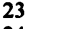 & 37 & $\mathbf{M}$ & $\mathbf{R}$ & C & ed suicide \\
\hline 24 & 68 & $\mathbf{M}$ & $\mathbf{R}: \mathbf{S}$ & $\mathbf{H}$ & nial tumour (glioma) \\
\hline 5 & 45 & $\mathbf{F}$ & $\mathbf{S}$ & $\mathbf{H}$ & Cere \\
\hline 66 & 54 & $\mathbf{M}$ & $\mathbf{S}$ & $\mathbf{H}$ & Intracranial tumour (g \\
\hline & 60 & $\mathbf{M}$ & $\mathbf{S}$ & $\mathbf{H}$ & al tumour (glioma) \\
\hline 28 & 70 & $\mathbf{F}$ & $\mathbf{S}$ & $\mathbf{H}$ & Cerebral infarction \\
\hline & 37 & $\mathbf{M}$ & $\mathbf{S}$ & $\mathbf{H}$ & I tumour (glioma) \\
\hline 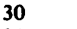 & 48 & $\mathbf{M}$ & $\mathbf{S}$ & $\mathbf{H}$ & laemorrhage \\
\hline 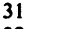 & 31 & $\mathbf{M}$ & $\mathbf{S}$ & $\mathbf{H}$ & Pulmonary embolism \\
\hline 32 & 68 & $\mathbf{M}$ & $\mathbf{S}$ & $\mathbf{H}$ & Myocardial infarction \\
\hline 33 & 68 & $\mathbf{M}$ & $\mathbf{S}$ & $\mathbf{H}$ & Mycocardial infarction \\
\hline 34 & 41 & $\mathbf{M}$ & $\mathbf{S}$ & $\mathbf{H}$ & $\begin{array}{l}\text { Carcinoma of lung with cerebral } \\
\text { secondaries }\end{array}$ \\
\hline & 62 & $\mathbf{M}$ & $\mathbf{S}$ & $\mathbf{H}$ & Cerebral haemorrhage \\
\hline
\end{tabular}

$\mathbf{S}=$ Sural; $\mathbf{R}=$ Radial; $\mathbf{H}=$ Hospital; $\mathbf{C}=$ = Coroner's Court.

Numbers in parentheses are case numbers from Swallow (1966) and indicate that the anterior tibial nerves were also studied in these patients.

All sections were photographed at a magnification of 욱 $\times 250$ on a Zeiss Ultraphot 11 Camera-microscope using $9 \times 12 \mathrm{~cm}$ Ilford panchromatic plates. Enlargements were made onto bromide paper and two sets of prints were made.

(a) All sections were printed at a magnification of $N$ $\times 500$ for the estimation of fibre density. 
(b) Selected nerves were enlarged to $\times 1,000$ for the measurement of fibre diameter. During the process of enlarging, magnification was checked regularly using a plate on which the micrometer scale had been photographed.

Details of the method of fibre counting, of the measurement of fascicular area, and of the construction of histograms are given by Swallow (1966). In the prepara-

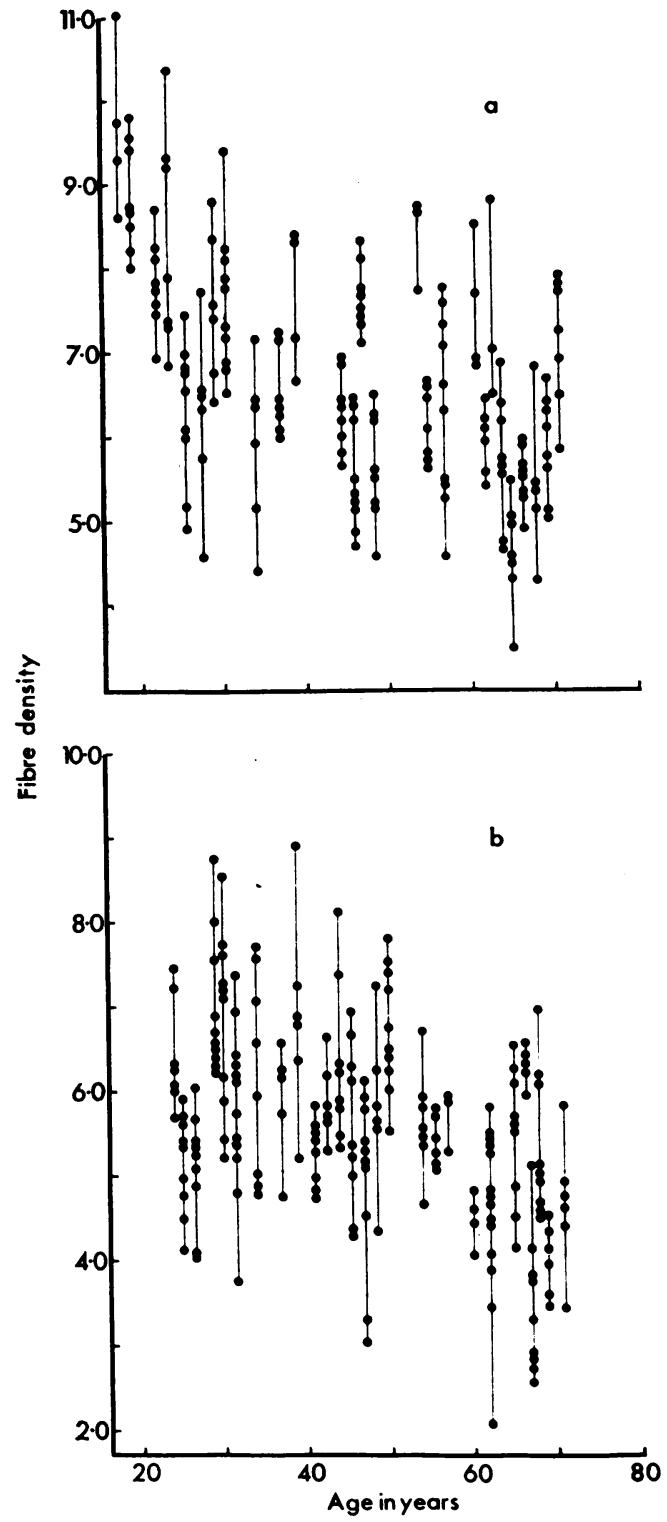

FIG. 1. Fibre density (thousand fibres/sq. $\mathrm{mm}$ ) of individual fascicles of the radial nerve (a) and the sural nerve (b) plotted against the subject's age. Values for different fascicles of the same nerve are joined by a line. tion of histograms all fibres with a diameter of $2 \mu$ or less were grouped together; larger fibres were subdivided into $1 \mu$ groups.

\section{RESULTS}

VARIATION OF FASCICULAR SIZE The diameter of individual fascicles varied from $0.075 \mathrm{~mm}$ to $0.69 \mathrm{~mm}$ for the radial nerve, and from $0.056 \mathrm{~mm}$ to $0.742 \mathrm{~mm}$ for the sural nerve. As in the previous study, fascicles with a diameter of less than $100 \mu$ were considered to be unsuitable for the estimation of fibre density. There were five such fascicles in the 27 radial nerves and 13 in the 27 sural nerves.

For the remaining 182 radial nerve fascicles the mean diameter was $0.373 \mathrm{~mm}$ (S.D. 0.13). In 217 sural nerve fascicles with a diameter greater than $100 \mu$, the mean diameter was $0.338 \mathrm{~mm}$ (S.D. 0.11). There was no correlation between fascicular diameter and the age of the subject.

VARIATION IN FIBRE DENSITY Fibre density may be expressed as the number of fibres per sq. $\mathrm{mm}$ of intra-perineural area. This was calculated for each fascicle and results are shown graphically in Figure 1.

In the 182 radial nerve fascicles the highest fibre density was 11.04 thousand fibres/sq. $\mathrm{mm}$ in a 17-year-old male, and the lowest was 3.48 thousand fibres/sq. $\mathrm{mm}$ in a 65 -year-old subject.

In the 217 sural nerve fascicles the highest fibre density was 8.99 thousand fibres/sq. $\mathrm{mm}$ in a subject aged 39, and the lowest was 2.04 thousand fibres/sq. $\mathrm{mm}$ in a 62-year-old subject.

Mean fibre density for each of the 54 nerves has been calculated by adding together the numbers of myelinated fibres in each fascicle (fascicles with a diameter of less than $100 \mu$ being ignored), and dividing the total number of fibres in each nerve by the sum of the intra-perineural areas of individual fascicles. In Fig. 2, the mean fibre density is plotted against age, results for the radial nerve being shown above and those for the sural nerve below.

In both nerves there is a tendency for mean fibre density to decrease with age. Using Spearman's Ranking test, the inverse relationship between fibre density and age was significant at the 0.01 probability level for the radial nerve, and the 0.05 probability level for the sural nerve (for the radial nerves $R=0.56$; for the sural nerves $R=0.43$ ).

Figure 2 does not suggest an obvious difference between the sexes, and when the mean values for males and females were calculated, there was no significant difference between them in either the radial or the sural nerve (Table II).

The mean figure for fibre density for various age 
TABLE II

MEAN AND S.D. FOR FIBRE DENSITY OF NERVES FROM MALE AND FEMALE SUBJECTS (THOUSAND FIBRES/SQ. MM)

\begin{tabular}{lllll} 
Radial & & & \multicolumn{2}{l}{ Sural } \\
\cline { 1 - 1 } \cline { 5 - 5 } Males & Females & & Males & Females \\
\hline (17 nerves) & (10 nerves) & & 19 nerves) & (8 nerves) \\
$7.16 \pm 1.28$ & $6.29 \pm 1.08$ & & $5.56 \pm 0.6$ & $5.82 \pm 1.2$
\end{tabular}
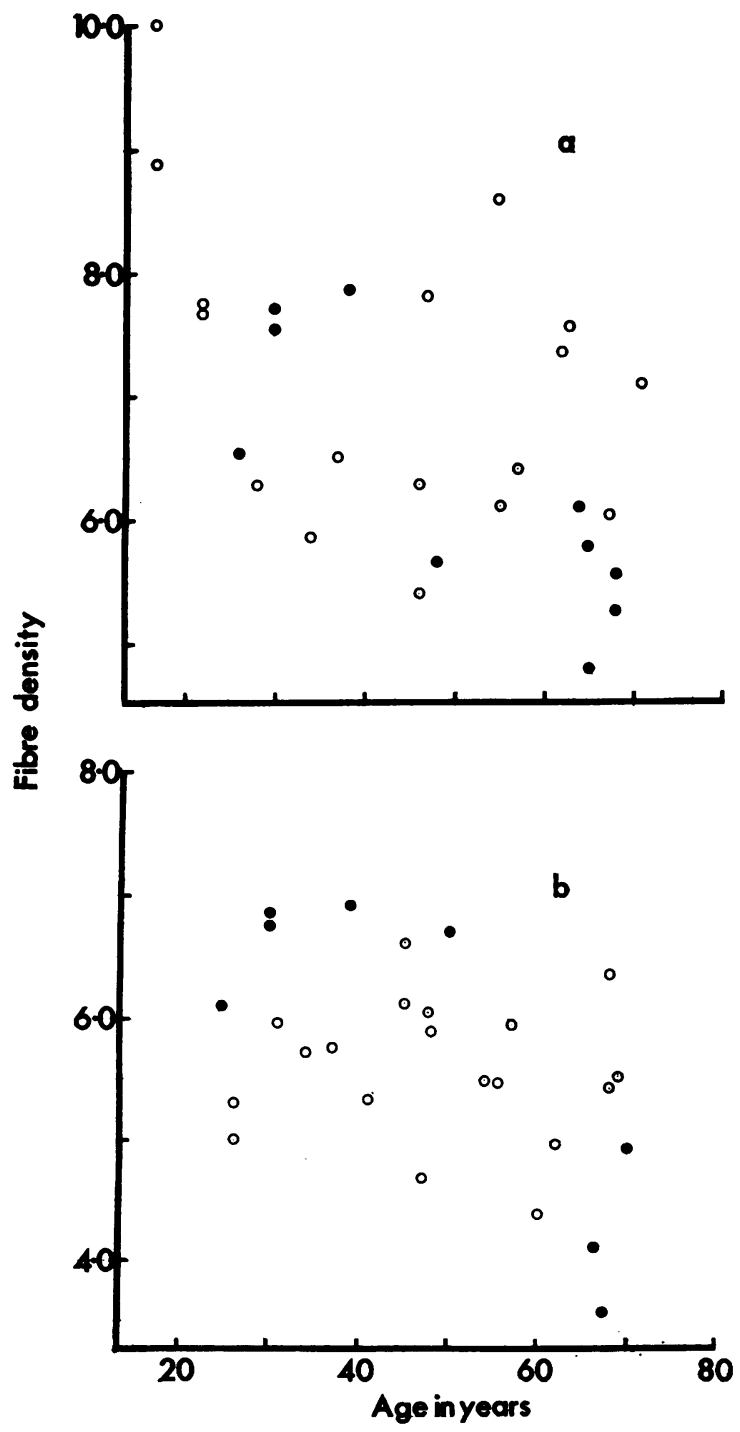

FIG. 2. Mean fibre density (thousand fibres/sq. $\mathrm{mm}$ ) of the radial nerve (a) and the sural nerve (b) plotted against the subject's age. (Open circles for male and filled circles for female subjects).
TABLE III

FIBRE DENSITY IN DIFFERENT AGE GROUPS

\begin{tabular}{|c|c|c|c|c|}
\hline \multirow[b]{2}{*}{ Age } & \multicolumn{2}{|l|}{ Radial } & \multicolumn{2}{|l|}{ Sural } \\
\hline & $\begin{array}{l}\text { Nerves } \\
\text { (no.) }\end{array}$ & $\begin{array}{l}\text { Mean fibre density } \\
\text { and S.D. }\end{array}$ & $\begin{array}{l}\text { Nerves } \\
\text { (no.) }\end{array}$ & $\begin{array}{l}\text { Mean fibre density } \\
\text { and S.D. }\end{array}$ \\
\hline $\begin{array}{l}17-39 \\
40-59 \\
60-80\end{array}$ & $\begin{array}{r}11 \\
7 \\
9\end{array}$ & $\begin{array}{l}7.44 \pm 1.34 \\
6.37 \pm 1.05 \\
5.98 \pm 1.07\end{array}$ & $\begin{array}{r}9 \\
10 \\
8\end{array}$ & $\begin{array}{l}6.13 \pm 1.11 \\
5.78 \pm 0.90 \\
4.78 \pm 1.08\end{array}$ \\
\hline
\end{tabular}

TABLE IV

FIBRE DENSITY IN TWO LIMBS (THOUSAND FIBRES/SQ. MM)

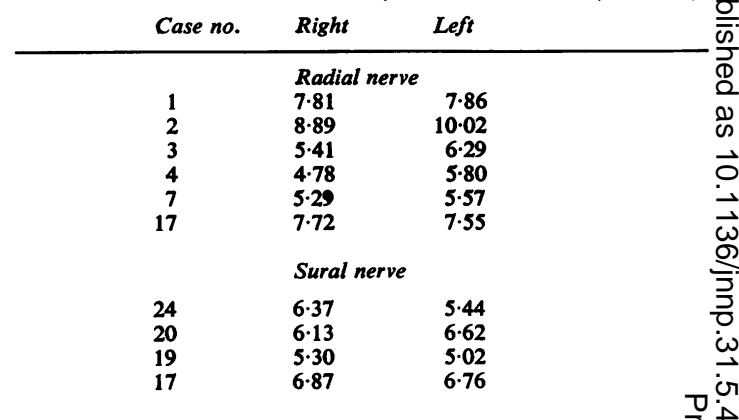

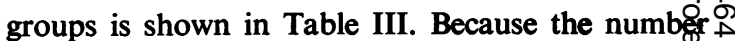
of nerves in each group was small, the differences을 between the mean figures for consecutive age groups failed to reach statistical significance.

There were six cases in which the radial nerves? were taken from both arms, and four cases in whies the sural nerves were taken from both legs. Figures for fibre density are given in Table IV, from whis it can be seen that in any one subject there was little 9 difference between the nerves on the two sides.

COMPARISON BETWEEN ANTERIOR TIBIAL, RADIAL, AND SURAL NERVES When the previous results of Swallow (1966) are added to those of the present study, there $\stackrel{\square}{\Phi}$ were six subjects from whom both the anterior tibial and the sural nerve were taken (see Table I). Mean $\frac{0}{3}$ figures for fibre density in the two sets of nerves were 4.73 thousand fibres/sq. $\mathrm{mm}$ (S.D. 1.03) for the six anterior tibial nerves and 5.62 thousand fibres/ sq. mm (S.D. 1.11) for the six sural nerves; this difference is not statistically significant.

In 16 subjects, specimens of both the anterior tibial nerve and the radial nerve were taken. The mean figure for fibre density in the 16 anterior tibial $\frac{0}{3}$ nerves-expressed as thousand fibres/sq. $\mathrm{mm}$ - was $4.75 \pm 1 \cdot 31$, whereas the mean figure for the 16 음 radial nerves was $6.94 \pm 1 \cdot 18$, the difference being $\frac{D}{O}$ statistically significant $(P<0.05)$.

Sural and radial nerves from the same subjects $N$ were available in nine cases. The mean figure for fibre density for the nine sural nerves $(5.84 \pm 0.95)$ 
was again less than that for the nine radial nerves $(6.61 \pm 0.95)$, the difference being statistically significant $(P<0.05)$.

VARIATION IN FIBRE SIZE AND DISTRIBUTION Seventeen radial nerves and 16 sural nerves were used for the study of fibre diameter. Care was taken to include nerves from all age groups.

Fibre diameter measurements were made on one or more large fascicles, measuring between 600 and 1,000 fibres in each case.

In both the radial and the sural nerve there was a bimodal distribution of fibre diameter with peaks at 3-6 $\mu$ and 9-13 $\mu$. An example is shown in Figure 4c. In a previous study on the anterior tibial nerve, it was found that the proportion of large myelinated fibres tended to decrease with increasing age, the inverse relationship between the proportion of large fibres and the subject's age being significant at the $5 \%$ level by Spearman's Ranking test (Swallow, 1966). In the present material the proportion of large fibres (9-13 $\mu$ inclusive) for the radial nerve showed no significant decrease with increasing age, whereas for the sural nerve, the inverse relationship between the proportion of large fibres and the subject's age was significant at the 0.05 probability $(R=0.49)$. Results for individual nerves are given in the appendices.

FIBRE DENSITY AND FIBRE DIAMETER IN PATHOLOGICAL NERVES The effects of subacute combined degeneration and alcoholic neuropathy on fibre density and fibre diameter in the anterior tibial nerve were originally described by Greenfield and Carmichael (1935). Subsequently Garven, Gairns, and Smith (1962) described changes in the anterior tibial nerve due to obliterative vascular disease.

The two examples given below are intended to illustrate the value of fibre density and fibre diameter measurement in patients with pathological changes affecting the sural nerve.

Case 1: Alcoholic Neuropathy Mr. A. F. (N.H. A16801), aged 47, had been a heavy drinker (at least one bottle of gin per day) for seven to eight years before his admission to the National Hospital, Queen Square, under the care of Professor R. W. Gilliatt in March 1964. For two years his appetite had been poor and for one year there had been deterioration of vision. In the year before attending hospital, he noticed numbness and pins and needles in the feet and in the lower part of his legs; this was associated with ataxia, particularly when walking in the dark.

On examination, there was evidence of intellectual impairment. Both optic discs were pale with bilateral paracentral scotomata. There was nystagmus on lateral gaze. In the motor system, he showed tremor of out- stretched hands, but no wasting or weakness of the limbs. The deep tendon reflexes were sluggish but present except for the ankle jerks which were absent. There was a glove-and-stocking pattern of superficial sensory loss to pin-prick and cotton wool which was more marked in the legs than the arms; in the former it extended to just below the knees. Position sense was impaired in the toes and vibration sense lost below the knees. The liver was easily palpable below the costal margin. A grossly abnormal pyruvate tolerance test was considered to be compatible with alcoholic polyneuropathy. Considerable improvement of his clinical condition followed the complete withdrawal of alcohol and parenteral vitamin supplements.

Case 2: Thalidomide Neuropathy Mrs. C. F. (M.H. G.22497), aged 55, began taking thalidomide (Distival) as a regular nocturnal sedative in 1959. Within a few months she noticed paraesthesiae in the right foot, later spreading to involve the left foot. She continued to take the drug regularly for two years, during which time her symptoms slowly progressed.

She was admitted to the Middlesex Hospital under the care of Dr. Michael Kremer in November 1963. Although she had received no thalidomide for nearly two years, she still complained of paraesthesiae, which she thought had become more intense since stopping the drug. She described her symptoms in the legs as a tight feeling round the base of the toes and a drawing feeling over her ankles. These paraesthesiae were exacerbated by walking.

On examination, there was no abnormality in the cranial nerves or in the motor system. The tendon reflexes were normal except for the ankle jerks which were depressed; the plantar responses were flexor. Distal impairment of superficial sensation extended to the wrist in both upper limbs and to the mid-calf in both lower limbs. Marked hypersensitivity to pin-prick and light touch was present over the soles of the feet and palms of the hands. Appreciation of vibration and joint movement was preserved.

Sural nerve biopsies were carried out in both patients. No significant changes in connective tissue or in the intra-perineural blood vessels were present in either nerve, and no segmental demyelination was found in teased preparations of single fibres (Dr. R. G. Lascelles).

Portions of the transverse sections of the two pathological sural nerves and of the sural nerve from a control subject of similar age are shown at the same magnification in Figure 3. There appears on first inspection to be a reduction in fibre density in both pathological nerves compared with the control. On quantitative study, the apparent reduction in density was confirmed for the nerve from the alcoholic subject, the mean fibre density being 1.86 (thousand fibres/sq. $\mathrm{mm}$ ) compared with 5.50 for the control nerve. However, in the nerve from the patient intoxicated by thalidomide, the mean fibre density was 5.02 , which is within the normal range. 


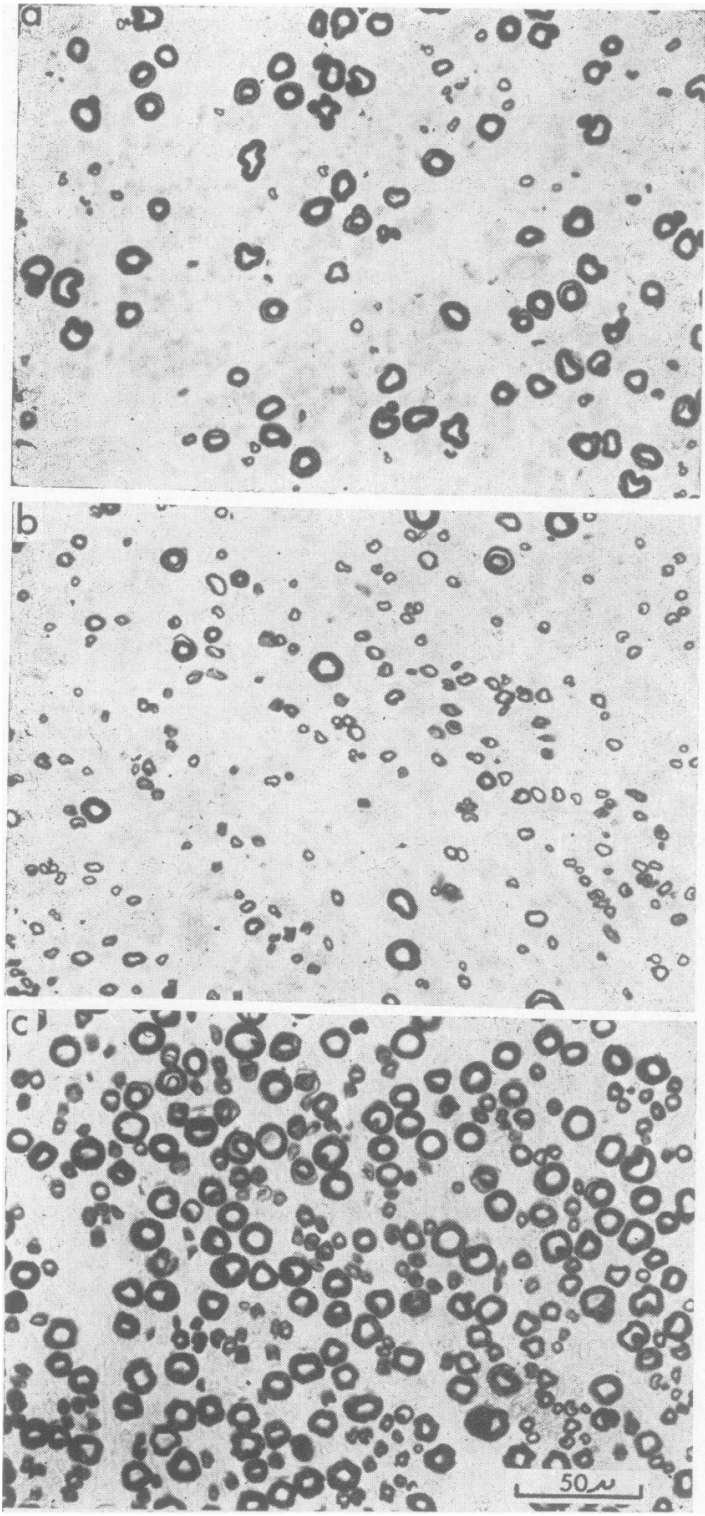

FIG. 3. (a) Portion of transverse section of the sural nerve from Case 1.

(b) Portion of transverse section of the sural nerve from Case 2.

(c) Portion of transverse section of the sural nerve from control subject (No. 26). Scale $50 \mu$.

Histograms of fibre diameter of the three nerves are shown in Figure 4. In the nerve from the alcoholic patient (Fig. 4a) the distribution of fibre diameters was similar to that of the control, suggesting that both large and small fibres were similarly affected by the disease process. However, in the nerve from the patient who had taken thalidomide $z$ (Fig. 4b) the large fibre peak has disappeared, the nerve consisting mainly of fibres less than $8 \mu$ in diameter. It might be thought that this indicates selective loss of large fibres, but further study showed an absolute increase in the number of small fibres compared with the control nerve, presumably due
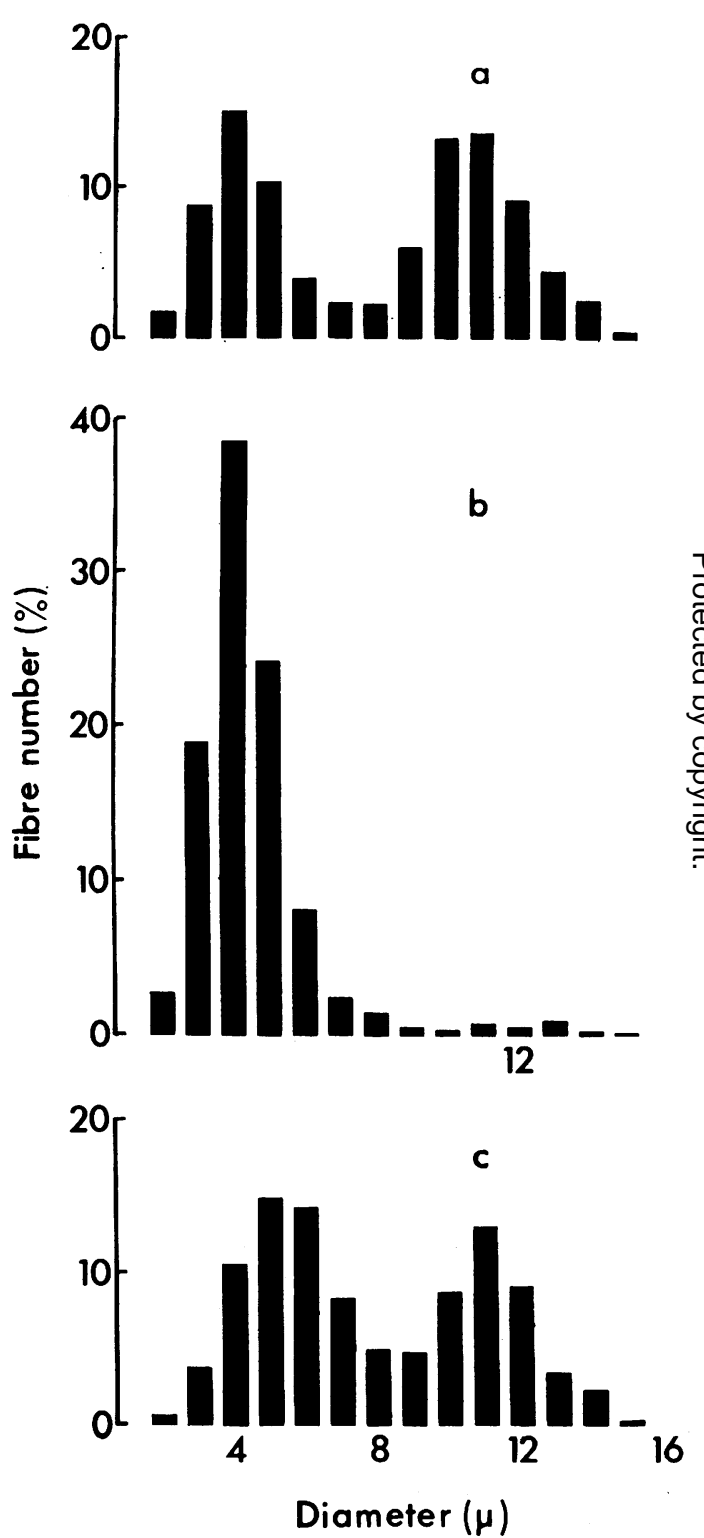

FIG. 4. Percentage histograms of fibre diameter of the sural nerves from: (a) Case 1. (b) Case 2. (c) Control subject (No. 26). 
to regeneration. This phenomenon, which has been found on more than one occasion in patients with thalidomide neuropathy, is discussed elsewhere (Fullerton and O'Sullivan, 1968).

For the present purpose, it is sufficient to conclude that the quantitative studies revealed significant differences between two nerves which might have been expected to show similar pathological changes.

\section{DISCUSSION}

In the previous study by Swallow (1966), the anterior tibial nerve at the site of biopsy was either a single nerve trunk or split into two easily recognizable branches. It was therefore possible to take either the whole nerve trunk or both its branches and to count all the myelinated fibres present. In the present study the radial nerve and the sural nerve were often found to consist of several branches at the level of the biopsy. As only the main branch was taken, figures for the total number of myelinated fibres would have little meaning and have not been given in the present paper.

The presentation of results in the form of fibre density is open to the objection that the results are affected by changes in fascicular area as well as by changes in fibre population. However, there is no reason to believe that the decreasing fibre density, which we have shown to occur with increasing age in the present material, was due to fascicular swelling. In fact, fascicular area showed no significant trend with age. The present results, therefore, suggest that some diminution in fibre numbers occurs with increasing age; a similar trend was demonstrated by Swallow in the case of the anterior tibial nerve on the basis of total fibre counts.

A difference between the arm and the leg has been shown in relation to the proportion of large myelinated fibres. In the anterior tibial nerve there was a significant fall in the proportion of large myelinated fibres with increasing age; in the present study a similar trend has been demonstrated for the sural nerve but not for the radial nerve. It might be suggested that this difference between nerves of the upper and lower limbs is related to the greater susceptibility of the latter to trauma and vascular disease.

There are few figures for fibre density in the radial nerve or the sural nerve available in the literature, and we are not aware of any previous study of the effects of age on fibre diameter and density in these nerves. Dyck, Beahrs, and Miller (1965) and Dyck and Lambert (1966) have published figures for human sural nerves taken from subjects with no evidence of peripheral nerve disease. Their figures were higher than those of the present study, probably due to differences of technique in fixation, staining, and the measurement of fascicular area. Ranson, Droegemueller, Davenport, and Fisher (1935) in a study of human cutaneous nerves showed that in the superficial radial nerve the small diameter peak was at $2-4 \mu$, and the large diameter peak was at 8-12 $\mu$. Only one nerve was examined and fibre density was not calculated. Sunderland, Lavarack, and Ray (1949) and Lavarack, Sunderland, and Ray (1951) studied fibre size in normal human radial and sural nerves and described fibres of slightly larger diameter than any seen in the present work; this difference may be related to the site of nerve section which was proximal in their study. Lavarack et al. (1951) made the specific comment that fibre branching tended to reduce maximal diameter when distal sections of the same nerves were studied.

It may therefore be concluded from our data and from previous studies that comparisons between one set of data and another can only be made when sections have been taken at the same level and processed by the same technique.' When a standardized procedure is used, the quantitative study of pathological radial and sural nerve biopsies may be expected to provide clinically useful information of the kind illustrated by the two patients described in the present paper.

\section{SUMMARY AND CONCLUSIONS}

The myelinated fibre content of the radial nerve and the sural nerve has been studied in necropsy specimens from subjects between the ages of 17 and 71 years with no history of peripheral nerve disease. Twenty-seven nerves were obtained from 21 subjects for the radial nerve, and 27 nerves were obtained from 23 subjects for the sural nerve. There was a significant fall in fibre density with increasing age in both the radial nerve and the sural nerve.

The fibre diameter spectrum was studied in 17 radial nerves and 16 sural nerves. There was a decrease in the proportion of large diameter fibres with increasing age in the sural nerve, but not in the radial nerve.

Two case histories have been described which illustrate the value of estimating fibre density and fibre diameter in pathological sural nerves.

The importance of a standardized technique has been emphasized.

The work was carried out in the University Department of Clinical Neurology with the aid of a generous grant from the National Fund for Research into Crippling Diseases. We wish to thank Professor R. W. Gilliatt for encouragement and help. We also wish to thank Miss C. A. 
Botwright and Mr. W. F. Hinkes for their technical Assistance.

\section{REFERENCES}

Dyck, P. J., Beahrs, O. H., and Miller, R. H. (1965). Peripheral nerves in hereditary neural atrophies: number and diameters of myelinated fibers. Pp. 673-677. In Proc. 6th Int. Congr., Electroenceph. clin. Neurophysiol., Vienna, Verlag der Weiner Medizinischen Akademie.

$\longrightarrow$, and Lambert, E. H. (1966). Numbers and diameters of nerve fibers and compound action potential of sural nerves: controls and hereditary neuromuscular disorders. Trans. Amer. neurol. Ass., 91, 214-217.

Fullerton, P. M., and O'Sullivan, D. J. (1968). Thalidomide neuropathy; a clinical, electrophysiological and pathological follow up. In preparation.

Garven, H. S., Gairns, F. W., and Smith, G. (1962). The nerve fibre populations of the nerves of the leg in chronic occlusive arterial disease in man. Scot. med. J., 7, 250-265.
Greenfield, J. G., and Carmichael, E. A. (1935). The peripheral nerves in cases of subacute combined degeneration of the cord. Brain $58,483-491$.

Gutmann, E., and Sanders, F. K. (1943). Recovery of fibre numbers and diameters in the regeneration of peripheral nerves? J. Physiol. (Lond.), 101, 489-518.

Lavarack, J. O., Sunderland, S., and Ray, L. J. (1951). The branchingo of nerve fibres in human cutaneous nerves. J. comp. Neurol., $94 \mathrm{Q}$ 293-311.

Ranson, S. W., Droegemueller, W. H., Davenport, H. K., anf Fisher, C. (1935). Number, size and myelination of the sensor fibres in the cerebrospinal nerves. Res. Publ. Ass. nerv. menr. Dis., 15.

Sunderland, S., Lavarack, J. O., and Ray, L. J. (1949). The calibre of nerve fibres in human cutaneous nerves. J. comp. neurol., 910 87-101.

Swallow, M. (1966). Fibre size and content of the anterior tibia nerve of the foot. J. Neurol. Neurosurg. Psychiat., 29, 205-213

\section{APPENDIX I}

RADIAL NERVES

NUMBERS OF FIBRES IN EACH DIAMETER CATEGORY EXPRESSED AS PERCENTAGE OF THE SAMPLE MEASURED

\begin{tabular}{|c|c|c|c|c|c|c|c|c|c|c|c|c|c|c|c|c|c|c|}
\hline $\begin{array}{l}\text { Case } \\
\text { no. }\end{array}$ & Nerve & Age & $\begin{array}{l}\text { Mean } \\
\text { fibre } \\
\text { density }\end{array}$ & 2 & 3 & 4 & 5 & 6 & 7 & 8 & 9 & 10 & 11 & 12 & 13 & 14 & 15 & $16 \mu$ \\
\hline $\begin{array}{l}2 \\
1\end{array}$ & Radial & 17 & 10.02 & $2 \cdot 1$ & $\begin{array}{r}7 \cdot 7 \\
12 \cdot 1\end{array}$ & $14 \cdot 5$ & $12 \cdot 0$ & $11 \cdot 3$ & $8 \cdot 2$ & 8.0 & $9 \cdot 7$ & $12 \cdot 2$ & $10 \cdot 1$ & 3.4 & 0.6 & & & \\
\hline $\begin{array}{r}1 \\
14\end{array}$ & ", & $\begin{array}{l}22 \\
28\end{array}$ & $\begin{array}{l}7 \cdot 86 \\
6 \cdot 28\end{array}$ & $\begin{array}{l}4.0 \\
1.9\end{array}$ & $\begin{array}{l}12 \cdot 1 \\
11 \cdot 2\end{array}$ & $\begin{array}{l}18 \cdot 8 \\
17 \cdot 3\end{array}$ & $\begin{array}{l}16 \cdot 2 \\
12 \cdot 1\end{array}$ & $\begin{array}{r}11 \cdot \\
8 .\end{array}$ & $\begin{array}{l}6 \cdot 7 \\
5.6\end{array}$ & $\begin{array}{l}7 \cdot 4 \\
5 \cdot 7\end{array}$ & $\begin{array}{l}9 \cdot 7 \\
9 \cdot 5\end{array}$ & $\begin{array}{r}7 \cdot 6 \\
12 \cdot 4\end{array}$ & $\begin{array}{l}3.9 \\
9 \cdot 2\end{array}$ & $\begin{array}{l}1.9 \\
4.6\end{array}$ & $1 \cdot 3$ & 0.3 & 0.2 & \\
\hline $\begin{array}{r}14 \\
6\end{array}$ & ", & $\begin{array}{l}28 \\
34\end{array}$ & $\begin{array}{l}0.28 \\
5.87\end{array}$ & $\begin{array}{l}1 \cdot 9 \\
1 \cdot 1\end{array}$ & $\begin{array}{r}11.2 \\
4.0\end{array}$ & $\begin{array}{r}1 / 3 \\
9.8\end{array}$ & $\begin{array}{l}12 \cdot 1 \\
13 \cdot 3\end{array}$ & 14.8 & $\begin{array}{r}3.0 \\
13.0\end{array}$ & $8 \cdot 1$ & $\begin{array}{l}y \cdot 3 \\
5 \cdot 8\end{array}$ & $\begin{array}{r}7 \cdot 4 \\
7 \cdot 4\end{array}$ & $9 \cdot 4$ & $\begin{array}{l}4 \cdot 0 \\
7 \cdot 1\end{array}$ & $\begin{array}{l}1 \cdot 3 \\
4 \cdot 0\end{array}$ & 1.8 & $\begin{array}{l}0.2 \\
0.5\end{array}$ & \\
\hline 3 & " & 46 & $5 \cdot 41$ & $1 \cdot 3$ & $3 \cdot 7$ & $11 \cdot 3$ & 9.4 & 6.7 & $7 \cdot 1$ & $7 \cdot 3$ & 6.0 & 6.5 & $11 \cdot 7$ & $11 \cdot 7$ & 9.6 & $5 \cdot 7$ & $1 \cdot 3$ & . \\
\hline 9 & 3 & 47 & $7 \cdot 83$ & $4 \cdot 6$ & $10 \cdot 6$ & $12 \cdot 5$ & 7.6 & $6 \cdot 3$ & 4.9 & $4 \cdot 4$ & 6.0 & $7 \cdot 9$ & 9.8 & 11.9 & 6.8 & $4 \cdot 3$ & $2 \cdot 0$ & $\vec{D}$ \\
\hline 13 & " & 55 & 8.63 & $1 \cdot 2$ & $7 \cdot 7$ & $17 \cdot 0$ & $15 \cdot 1$ & 10.5 & $7 \cdot 1$ & 6.4 & 5.9 & $8 \cdot 2$ & 9.3 & $8 \cdot 1$ & 2.5 & 0.8 & 0.2 & مق \\
\hline 10 & $"$ & 57 & 6.41 & $2 \cdot 2$ & $7 \cdot 7$ & $15 \cdot 3$ & 14.0 & $8 \cdot 6$ & 4.9 & $4 \cdot 8$ & 5.7 & $3 \cdot \overline{7}$ & $8 \cdot 3$ & 11.0 & $9 \cdot 7$ & 2.6 & 0.4 & \\
\hline 15 & "3 & 62 & $6 \cdot 11$ & $4 \cdot 3$ & 6.9 & 8.6 & 6.7 & $6 \cdot 2$ & 6.4 & $4 \cdot 4$ & $7 \cdot 3$ & $9 \cdot 3$ & 9.9 & $8 \cdot 1$ & 10.6 & 5.9 & 3.6 & \\
\hline 16 & 3 & 63 & $\mathbf{7} \cdot \mathbf{3 8}$ & $1 \cdot 8$ & 7.9 & $11 \cdot 2$ & 10.0 & 8.6 & $7 \cdot 7$ & 6.0 & $7 \cdot 7$ & 10.4 & 13.0 & $10 \cdot 6$ & 3.7 & 1.4 & 0.1 & \\
\hline 11 & $"$ & 63 & $7 \cdot 57$ & $2 \cdot 0$ & $10 \cdot 5$ & $15 \cdot 3$ & 11.4 & $6 \cdot 1$ & $4 \cdot 8$ & 6.5 & $7 \cdot 7$ & $15 \cdot 2$ & $13 \cdot 3$ & $5 \cdot 2$ & $1 \cdot 2$ & 0.6 & 0.2 & $0 . \bar{b}$ \\
\hline 4 & $"$ & 65 & $4 \cdot 78$ & 0.9 & $5 \cdot 5$ & $10 \cdot 6$ & $11 \cdot 8$ & 9.6 & $6 \cdot 1$ & $5 \cdot 2$ & 3.9 & 5.7 & 8.9 & $9 \cdot 3$ & $9 \cdot 2$ & $9 \cdot 3$ & 2.8 & 1.0 \\
\hline 4 & ", & 65 & $5 \cdot 80$ & $1 \cdot 1$ & 4.0 & 8.7 & 9.9 & $9 \cdot 4$ & 6.5 & $7 \cdot 0$ & $5 \cdot 7$ & $7 \cdot 3$ & 10.9 & $13 \cdot 3$ & $10 \cdot 1$ & 3.8 & 1.9 & 0建 \\
\hline 7 & ", & 68 & $5 \cdot 27$ & $4 \cdot 3$ & $7 \cdot 5$ & $10 \cdot 7$ & 9.9 & $8 \cdot 5$ & 6.5 & $5 \cdot 3$ & $4 \cdot 7$ & 5.9 & $6 \cdot 8$ & $7 \cdot 7$ & $8 \cdot 9$ & $8 \cdot 1$ & 3.4 & $1 \cdot \mathrm{E}$ \\
\hline 7 & ", & 68 & $5 \cdot 57$ & $7 \cdot 2$ & $13 \cdot 2$ & 16.0 & $9 \cdot 4$ & 6.0 & $4 \cdot 6$ & $6 \cdot 2$ & $6 \cdot 2$ & 9.5 & $9 \cdot 1$ & 6.4 & $4 \cdot 1$ & 1.6 & 0.5 & 으 \\
\hline 24 & ", & 68 & 6.06 & $0 . \overline{8}$ & 10.0 & 13.6 & $9 \cdot 8$ & $9 \cdot 0$ & 9.5 & $7 \cdot 0$ & 5.6 & 5. & 8.9 & 9.5 & 5.8 & 3.4 & $1 \cdot 3$ & $0 \cdot \bar{z}$ \\
\hline 12 & & 71 & $7 \cdot 14$ & $3 \cdot 7$ & $11 \cdot 7$ & $16 \cdot 3$ & $11 \cdot 5$ & $8 \cdot 2$ & $8 \cdot 2$ & $8 \cdot 2$ & $6 \cdot 3$ & 6.8 & $6 \cdot 1$ & $6 \cdot 1$ & $3 \cdot 7$ & $2 \cdot 0$ & 0.8 & $0 ?$ \\
\hline
\end{tabular}

${ }^{1}$ Diameter measurements made on $600-1,000$ fibres in each nerve.

\section{APPENDIX II}

SURAL NERVES

NUMBERS OF FIBRES IN EACH DIAMETER CATEGORY EXPRESSED AS PERCENTAGE OF THE SAMPLE MEASURED ${ }^{1}$

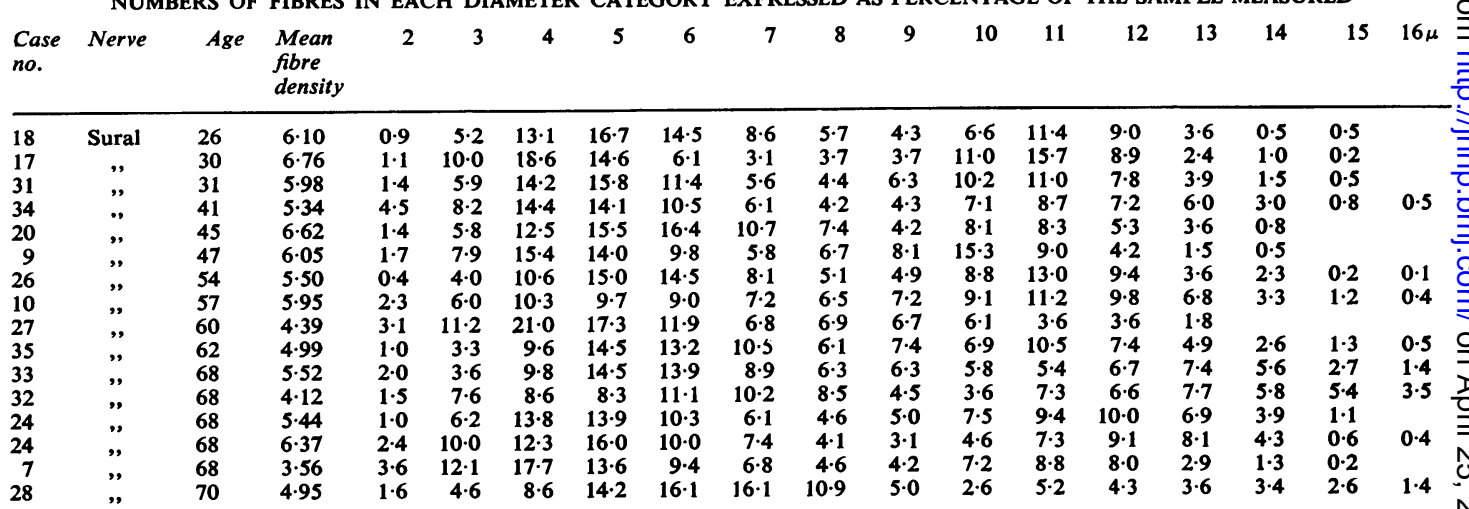

${ }^{1}$ Diameter measurements made on $600-1,000$ fibres in each nerve. 